\title{
TRATAMIENTO AMbULATORIO CON CLOROMICETINA EN UN GRUPO DE NINOS CON TOS FERINA
}

\author{
Por los Dres. JULlo MENEGHELLO R. y ARTURO GALLO B. \\ Unidad Sanitaria "Santa Rosa". Catredras de Pediatria de los Profs. Arturo Baeza Goñi \\ y Jullo Meneghello R.
}

Tal vez en pocas enfermedades de la infancia se han ensayado más tratamientos que en la tos ferina. Ello se explica por la elevada mortalidad que produce en los menores de 6 meses y por la dramaticidad del acceso. También en pocas enfermedades hay mayor número de opiniones contradictorias acerca de la bondad o ineficacia de una terapéutica dada, principalmente porque aquel que cree observar algún efecto se apresura a comunicarlo, sin tener siempre presente que las diferentes modalidades clínicas que adopta la enfermedad dëpenden de un sinnúmero de factores.

El uso de algunos antibióticos, sin embargo, en especial la cloromicetina, parece tener base solida, por cuanto se ha demostrado franca inhibición in vitro del H. Pertussis y porque trabajos con buen número de pacientes arrojan impresión favorable. Así, Payne y colaboradores', en Bolívia, tratan 50 niños menores de 5 años con curación total entre el $3^{\circ}$ y $6^{\circ}$ día de tratamiento; Gray ${ }^{2}$ obtiene también resultados muy satisfactorios.

Canevari y Moscoso: 4, en Argentina; Macrae $^{5}$, en Inglaterra, y Barbera y colaboradores', en Italia, informan de resultados igualmente alentadores. Ultimamente, en una revisión de los casos consignados de la literatura mundial, Di Vito, de Italia, concluye que de 216 casos comunicados, el $83 \%$ curaron en pocos días, el $11 \%$ mejoraron y sólo hubo un $6 \%$ de fracasos.
En el Hospital de Niños Manuel Arriarán se han estado tratando los enfermitos de coqueluche con cloromicetina desde 1950, y la experiencia recogida se expone en el presente trabajo.

Material. - El material de estudio comprendia primitivamente 100 niños de distintas edades que consultaron por coqueluche a la Policlínica de Enfermedades Infecciosas del Hospital de Niños Manuel Arriarán durante el período epidémico de 1950-51. Después de la primera consulta, los enfermos fueron citados a controles periódicos cada 3 días y los inasistentes fueron visitados por personal de la Unidad Sanitaria, que practicó una encuesta domiciliaria e insistió en la concurrencia a la Policlínica. Sin embargo, 20 niños, que no volvieron después de la primera visita, no pudieron ser controlados por haber dado domicilio falso. Los 80 nfños restantes los clasificamos en 4 grupos:

Grupo 1: 19 niños tratados en forma completa y bien seguidos en su evolución.

Grupo 2: 18 enfermos en que el esquema del tratamiento no pudo completarse, pero que en todo caso recibieron la droga por un minimo de 5 días $\mathrm{y}$ fueron bien controlados.

Grupo 3: 15 niños en que no se pucio suministrar cloromicetina por diversas razones, pero que cumplieron todas las citaciones y que sirvieron como controles. 
Grupo 4: Los 28 casos restantes son aquéllos en que el control no pudo hacerse en forma satisfactoria y no se consideran en los resultados.

Debemos hacer notar que no hemos incluído los enfermos que consultaron con alguna complicación de la enfermedad (bronconeumionía, etc.), los que fueron generaImente hospitalizados.

Las edades fueron muy variables: 24 eran lactantes menores de 1 año y cl resto dió un promedio de 4 años de edad. El comienzo del tratamiento se inició, como promedio, a los 14.2 días del comienzo aparente de la enfermedad en el grupo 1 y a los 13.4 en el grupo 2 (cuadro 1). Para hacer el diagnóstico de coqueluche exigimos la coexistencia de 2 de los 4 factores siguientes:

1 . Cultivo bacteriológico positivo;

2 Acceso coqueluchoso típico en presencia del médico;

$3^{\circ}$ Antecedentes epidemiológico evidentes;

$4^{\circ}$ Eliminación de otros diagnósticos. les 42,9 con imágenes de peribronquitis y 10 con imágenes de atelectasias.

Los síntomas de mayor frecuencia fueron, además del típico acceso de tos, los vómitos, la anorexia y el decaimiento, que se presentaron en 23, 36 y 21 casos, respectivamente, del total de los grupos 1, 2 y 3 . La epistaxis, el edema palpebral y las hemorragias sub-conjurltivales fueron también frecuentes.

Tratamiento. - El esquema de tratamiento fué fijado arbitrariamente en la siguiente forma:

a) En los lactantes se dió $1 / 2$ cápsula de $250 \mathrm{mg}$ cada 6 horas, durante 5 días, luego la mitad de esta dosis por otros 5 días, totalizando $3.75 \mathrm{~g}$. La vía usada fué la bucal, recomendándose mezclar el contenido de la cápsula con miel o jarabe, con una tolerancia en general satisfactoria. En los pocos casos en que no fué posible usar esta vía, se indicó la colocación de la cápsula entera perforada, por via rectal, cada 12 horas.

Cuadro $\mathrm{N}^{2} 1$.

Caracteristicas de un grupo de 37 nin̄os enfermos de coqueluche y tratados con cloromicetina $y$ otro grupo control.

\begin{tabular}{|c|c|c|c|c|c|c|c|}
\hline & \multicolumn{4}{|c|}{$\mathbb{E d a d}$} & \multicolumn{3}{|c|}{ sintomas } \\
\hline & $\begin{array}{l}\text { Node } \\
\text { casos }\end{array}$ & $\begin{array}{l}\text { Menor } \\
\text { de } 1 \text { año }\end{array}$ & $\begin{array}{l}\text { Promedio } \\
\text { mayores } \\
\text { de } 1 \text { año }\end{array}$ & $\begin{array}{c}\text { Días } \\
\text { antes } \\
\text { trat. }\end{array}$ & Vómitos & $\begin{array}{l}\text { Ano- } \\
\text { rexia }\end{array}$ & $\begin{array}{l}\text { Decai- } \\
\text { miento }\end{array}$ \\
\hline Tratamiento completo & 19 & 10 & 4 a. & 14.2 & 14 & 13 & $B$ \\
\hline Tratamiento incompleto & 18. & 20 & $3: 9$ a. & 13.4 & 11 & 9 & 9 \\
\hline Controles & 25 & 4 & $3.7 \mathrm{a}$ & - & 8 & 14 & 6 \\
\hline
\end{tabular}

El estudio bacteriológico se practicó con la técnica corriente en medio Bordet. En total se practicaron 100 cultivos, de los cuales sólo 15 fueron positivos. Es de hacer notar que en 3 casos al cultivo viró de positivo a negativo, después del tratamiento, pero también en 2 casos tratados viró de negativo a positivo.

Fin la mayoría de los enfermos se practicó estudio tuberculínico y radioscopía de tórax. De 61 radioscopías practicadas, fueron informadas como norma- b) En los mayores de 2 años se siguió igual esquema, pero doblando la dosis, con un total de $7.5 \mathrm{~g}$.

\section{Resultados y comentario.}

Los resultados obtenidos se presentan en el cuadro 2.

El criterio de mejoría se refirió especialmente al sintoma tos, según la información dada por la madre y fué siempre mucho más evidente en cuanto a la intensidad que a la frecuencia de los ac- 
Cuadro N" 2 ,

Resultado del tratamiento con cloromicetina en 37 niños enfermos de tos ferina y comparado con 15 controles.

\begin{tabular}{|c|c|c|c|c|c|}
\hline & \multirow{2}{*}{$\begin{array}{l}\text { Mejoria evidente } \\
\text { (dias de enfermedat) }\end{array}$} & \multicolumn{4}{|c|}{ Recurrencia } \\
\hline & & $\begin{array}{c}\mathrm{N} \\
\operatorname{casos}\end{array}$ & $\begin{array}{l}\text { Días después } \\
\text { mejoria }\end{array}$ & $\begin{array}{l}\text { Duración } \\
\text { (dias) }\end{array}$ & $\begin{array}{l}\text { Alta } \\
\text { (días) }\end{array}$ \\
\hline Tratamiento completo & $23, T \pm 1,76 \mathrm{ds}$ & 7 & 8 & 10.5 & B1. \\
\hline Tratamiento inscmpleto & $2: \pm 3.54 n$ & 6 & 11 & 10 & 53 \\
\hline Controles & $4,51,5,56$ & - & - & $一$ & 59 \\
\hline
\end{tabular}

cesos. Si bien es posible que la exactitud de los datos se haya visto influído por tratarse de informaciones de terceras personas, era tan categórica en todos los casos, que creemos refleja la realidad. No nos parece que la información que pudiera dar la Enfermera del Hospital, que tiene a su cuidado varios niños, pueda ser más exacta. Además, la veracidad del informe familiar pudo ser comprobada en varias ocasiones en la consulta. La desaparición de los vómitos coincidió estrictamente con la disminución de la tos, el ánimo y el apetito se restablecieron, por lo general, 1 ó 2 días antes. Se observa que la eficasia del tratamiento fué evidente, como promedio a los 9.5 dias de iniciado éste en el grupo $1 \mathrm{y}$ a los 11.6 en el grupo 2. Como la cloromicetina se dió, como término medio, a los 14 días, la mejoría corresponde a los 24-25 días de enfermedad, en comparación con los 45 días del grupo control. Pero posteriormente, la tos continuó en los tratados hasta el plazo corriente en esta afección (60 dís más o menos), sin diferencia con el grupo control. En un número de casos cercano al $30 \%$ ( 7 en el grupo 1 y 6 en 61 grupo 2), la enfermedad sufrió una reintensificación a los pocos días de terminado el tratamiento. Este apareció a los 8 días como promedio en el grupo 1 y a los 11.5 días en el grupo 2, y duró aproximadamente 10 días en ambos casos, siendo tratados todos, excepto 3 , en forma sintomática. En 3 casos del grupo 2 hubo fracaso absoluto del tratamiento. La evolución de la enfermedad en los 3 grupos aparece representada esquemá- ticamente en el gráfico. En él se han colocado en la abcisa los días de evolución de la enfermedad y la ordenada es un valor abstracto que representa la intensidad y frecuencia del síntoma tos. La curva empieza con la primera consulta a la Políclínica, alrededor de los 14 dias de iniciada la afección. La caída brusca que se observa alrededor de 10

\section{ESQUEMA DE LA EVOLUCIÓN DE LA TOS FEGINA EN 2 GAUPOS DE NIM̂OS TRATADOS CON CLOAO- MICETINA Y OTRO GAUPO CONTROL - 1951.}

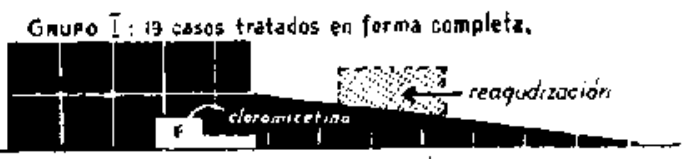

Grupo it: is casos tratados an forma parcial.
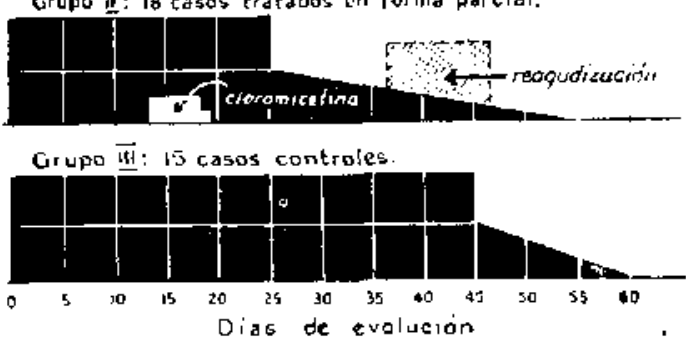

días después en los grupos 1 y 2 , corresponde a la opinión dada por la madre que el niño tosía mucho menos. Después la tos sigue disminuyendo hasta su curación total. La zona punteada corresponde a los casos en que se produjo la recrudescencia del sintoma después de suspendido el tratamiento. En el grupo 3 se observa que la tos se mantiene más o menos igual hasta los 45 días y que solo entonces empieza a disminuir.

Podemos agregar que en el grupo 4, en que el tratamiento hecho fué muy in- 
completo, el número de fracasos fué bastante alto y en los casos en que se observó alguna mejoría, fué casi de regla la reagudizaciôn posterior. En todo caso, en los enfermos en que se obtuvo aIgún resultado, éste coincidió con los plazos de los grupos $1 \mathrm{y} 2$.

No se observó relación de la mejoría ni con la edad del enfermo ni con la precocidad del tratamiento. En ninguno de nuestros casos aparecieron complicaciones en el curso del tratamiento.

En general, nuestros resultados son inferiores a la mayoría de los obtenidos por otros autores ${ }^{1}: 3+5$, que señalan la mejoria en un plazo más breve, de no más de 7 días, casi siempre con dosis más baja y durante un periodo más corto. No hemos encontrado citado el hecho que, después de la brusca disminución de la tos, ésta persiste con carácter más o menos banal por el tiempo normal de evolución de la enfermedad. Todos los autores hablan de curación total en un plazo corto, salvo en los fracasos del tratamiento. La recrudescencia después de suspendido el tratamiento, tan frecuente en nuestros casos, la hemos encontrado citada sólo en un caso de Payne'.

Esta disparidad no debe asombrarnos, tanto por la gran dificultad que existe pura establecer un criterio de mejoría en la tos ferina, como por la complejidad de factores que integran el acceso de tos. Estos mismos hechos nos hacen ser muy cautos en la interpretación de nuestros resultados. Sin embargo, podemos afirmar que, al menos en la mayoría de los casos tratados en forma completa, el acceso perdió su dramaticidad en forma evidente como consecuencia del tratamiento.

\section{Resumen.}

Se presenta la experiencia recogida en el tratamiento ambulatorio de 37 casos de tos ferina en niños de diversas edades, en comparación con un grupo de 15 controles. El estudio se hizo mediante citaciones cada 3 días a la Policlínica.
El tratamiento consistió en el suministro de $500 \mathrm{mg}$ diarios de cloromicetina durante 5 días en los lactantes y $1 \mathrm{~g}$ diario en los niños mayores. En los $\bar{\jmath}$ días siguientes la dosis fué rebajada a la mitad. La experiencia recogida puede resumirse en la siguiente forma:

1. Se confirma la dificultad para apreciar los resultados del tratamiento en la tos ferina.

2. El estudio ambulatorio de la enfermedad es sumamente difícil, pudiéndose hacer en forma satisfactoria sólo en 52 enfermos, de un grupo inicial de 100 .

3. Se observó una disminución franca de la frecuencia e intensidad de los accesos, alrededor de los 10 días de iniciado el tratamiento. La mejoría de la tos se acompañó siempre de la desaparición de los vómitos, la anorexia y el decaimiento. Sin embargo, la tos continuó en estos enfermos hasta enterar el plazo de 2 meses, que es el normal en esta enfermedad.

4. En un alto número de casos, la tos se reagudizó después de algunos días de suspendido el tratamiento. La frecuencia de este fenómeno fué más alta en Ios casos tratados en forma incompleta, en los cuales también se observó un mayor número de fracasos.

5. La impresión que nos queda es que la cloromicetina es una droga útil en el tratamiento de la tos ferina, pero que las dosis y la duración del tratamiento deben ser revisadas para mejorar los resiltados obtenidos.

\section{Summary.}

The authors report their studies on the ambulatory treatment of pertussis in children with chloromycetin. They treated 37 children with 15 control cases. All these cases were seen in the outpatient department and controled every three days. Treatment consisted in a daily dose of $500 \mathrm{mg}$ for infants and 1 gram for older children during 5 days, followed by one half the original dose for another 5 days. Although they recognize the difficulty of evaluating the 
results in the treatment of pertussis, they conclude that chloromycetin is a useful drug in this disease, but that both the criteria the dosage as well as the duration of treatment, must be reviewed to obtain better results. In many cases a decrease in frequency and intensity of the paroxysms was evident 10 days after treatment was begun. Improvement in coughing was always accompanied by disappearence of vomiting, anorexia and an improvement in the general condition of the child.

Nevertheless these patients continued coughing for two monts. In many cases there was a relapse after suspending treatment, specially in those cases only partialy treated.

\section{Bibliografia.}

1.-PAYNE, EUGEENE H. y col. - Pertussis treated with Cloramphentcol. J. A. M. A. 141: 1298, 1950 .

2-GRAY, J. D. - Observations on Chloramphenicol. Lancet I: 160, 1951.

3-CANEVARI, MÁRUCELO F. - La cloromicetina en la tos convnisa. Arch. Argentitinos de Ped. 2: 147, 1950 .

4--MOSOOSO Z., GASTON. - cloromycetin en la coqueluche. Arch. Argentinos de Ped. 32: 370, 1950.

5.-MACRAE, J. - Cloramphenicol in Whooping Cough. The Lancet $1: 480,18.50$.

6-BARBERA, L, y MARCHISSE, G. - La aureomicina e la Cloromicetina nella cura della Pertosse. La Pediatria 3: 177, 1950.

7.-DE VITO, CROVANNI. - La terapla antibiótica della Pertosse. Rassegna Medlca Medica 1: 23, 1950. 